\title{
HIGH TEMPORAL FREQUENCY BIOPHYSICAL AND STRUCTURAL VEGETATION INFORMATION FROM MULTIPLE REMOTE SENSING SENSORS CAN SUPPORT MODELLING OF EVENT BASED HILLSLOPE EROSION IN QUEENSLAND
}

\author{
B. Schoettker ${ }^{\mathrm{a}, *}$, R. Searle ${ }^{\mathrm{b}}$, M. Schmidt ${ }^{\mathrm{c}}$, S. Phinn ${ }^{\mathrm{a}}$ \\ ${ }^{a}$ The School of Geography, Planning and Environmental Management, The University of Queensland, 4072 St Lucia, \\ Queensland, Australia - b.schoettker@uq.edu.au \\ ${ }^{\mathrm{b}}$ Commonwealth Scientific and Industrial Research Organisation, Ecosciences Precinct, 4102 Dutton Park, Queensland, \\ Australia \\ ${ }^{c}$ Queensland Department of Environment and Resource Management, Remote Sensing Centre \\ Environment and Resource Sciences Ecosciences Precinct, 4102 Dutton Park, Queensland, Australia
}

\section{Commission VIII/8: Land}

KEY WORDS: vegetation, dynamic, multisensor, erosion modelling, MODIS, terrestrial, management.

\begin{abstract}
:
This study demonstrates the potential applicability of high temporal frequency information on the biophysical condition of the vegetation from a time series of the global Moderate Resolution Imaging Spectroradiometer (MODIS) Fraction of Photosynthetically Active Radiation absorbed by vegetation (FPAR) from 2000 to 2006 (collection 4; 8-day composites in $1 \mathrm{~km}$ spatial resolution) to improve modelling of soil loss in a tropical, semi-arid catchment in Queensland.

Combining the biophysical information from the MODIS FPAR with structural vegetation information from the Geoscience Laser Altimeter System on the Ice, Cloud, and land Elevation Satellite (ICESat) for six vegetation structural categories identified from a Landsat Thematic Mapper 5 (TM) and Enhanced Thematic Mapper 7 (ETM+) woody foliage projective cover product representing floristically and structurally homogeneous areas, dynamic vegetative cover factor (vCf) estimates were calculated. The dynamic vCf were determined in accordance with standard calculation methods used in erosion models worldwide. Time series of dynamic vCf were integrated into a regionally improved version of the Universal Soil Loss Equation (USLE) to predict daily soil losses for the study area. Resulting time series of daily soil loss predictions averaged over the study area coincided well with measures of total suspended solids (TSS) $(\mathrm{mg} / \mathrm{l})$ at a gauge at the outlet of the catchment for three wet seasons ( $\mathrm{R}^{2}$ of 0.96 for a TSS-event). By integrating the dynamic vCf into modified USLE, the strength of the dependence of daily soil loss predictions to the only other dynamic factor in the equation - daily rainfall erosivity - was reduced.
\end{abstract}

\section{INTRODUCTION}

\subsection{Motivation and aim}

The relevance of the vegetative cover components to mitigate soil loss effects by water and their potential to improve water quality downstream is widely accepted and has been proven valid over a range of ecosystems worldwide (Renard, Smith et al. 1997; Vrieling 2006; de Asis and Omasa 2007).

High quality information on the biophysical and structural properties of the total vegetation cover (TVC), optimally taken at high temporal frequency, is thus indispensable to support sustainable Natural Resource Management (NRM) of land and water. This is particularly valid in complex and highly dynamic savanna ecosystems, such as the tropical, semi-arid coastal catchments of Queensland adjacent to the Great Barrier Reef (GBR), where key challenges include declining water quality, land degradation and soil erosion, and terrestrial discharges into the lagoon (Hutchings and Hoegh-Guldberg 2008).

Remote sensing applications and broad-scale catchment modelling offer invaluable potential to complement classical field-based NRM in the assessment of temporal and spatial aspects of soil erosion in the savanna ecosystems of these tropical, semi-arid coastal catchments of Queensland (Searle and Ellis 2009). However, tropical savannas pose a particular challenge to remote sensing applications due to abundant senescent plant material being present at most times of the year in a structurally complex and heterogeneous landscape (Asner 1998), which all influence the biophysical and spectral properties of TVC at canopy and landscape (Asner and Wessman 1997).

For the detection of non-photosynthetic vegetation (NPV) in remote sensing applications the wavelength of photosynthetically active radiation (PAR) $(400-700 \mathrm{~nm})$ has also proven useful, since PAR is not always used for photosynthesis ('functional PAR') (Asner 1998; Thomas, Finch et al. 2006). A significant component of incident PAR can be absorbed by NPV material in savanna ecosystems, particularly in areas with a leaf area index (LAI) of less than 3.0; standing grass litter canopies absorbed almost as much PAR as green grass canopies (Asner 1998). How much PAR is absorbed at the landscape scale is greatly affected by overstorey (trees) but the relative differences in absorbed radiation are also affected by the understorey (mostly grasses) LAI.

Global remotely sensed products provide free of charge, high temporal estimates of biophysical properties that relate to relevant ecosystem structure and function and provide estimates of vegetation structure at different scales. Examples of these are

\footnotetext{
* Corresponding author.
} 
the products by the Moderate Resolution Imaging Spectroradiometer (MODIS) and the Geoscience Laser Altimeter System on the current NASA Ice, Cloud, and land Elevation Satellite (ICESat) (Scarth, Armston et al. 2010). Regionally developed Landsat Thematic Mapper (TM) and Enhanced Thematic Mapper (ETM+) products in Queensland also provide estimates of properties of the TVC that are highly relevant for supporting national and state NRM - specifically as these products are validated for the unique conditions in Australian savanna ecosystems (Danaher, Scarth et al. 2010; Scarth, Röder et al. 2010). The collective, remotely sensed information on certain vegetation properties could be valuable for erosion modelling studies in the tropical semi-arid savannas in Queensland.

The sensitivity of a time series of the global, biophysical Moderate Resolution Imaging Spectroradiometer (MODIS) Fraction of Photosynthetically Active Radiation absorbed by a canopy (FPAR) (Knyazikhin, Glassy et al. 1999) to a time series of regionally developed Landsat TM and ETM+ based green and non-green fractions of ground cover and vegetation structural categories (VSC) has been shown for a tropical semiarid catchment in Queensland, Australia, in an earlier study (Schoettker, Phinn et al. 2010; Schoettker, Scarth et al. 2010). In a multiple regression analysis (including interaction terms) $75 \%$ of the variability in dry season MODIS FPAR was explained by the Landsat datasets in a catchment of $9500 \mathrm{~km}^{2}$ that lies adjacent to the GBR (the Bowen/Broken subcatchment) (Schoettker, Scarth et al. 2010). The catchment has been considered an important contributor to terrestrial discharges into the GBR lagoon (Lewis, Sherman et al. 2009).

Which potential global and high temporal frequency biophysical products, such as the MODIS FPAR and the ICESat might have to complement regional remote sensing products for the mapping and monitoring of TVC properties relevant to erosion modelling has not been identified to date - specifically not in Australian savannas. The main aim of this research was thus to determine the global MODIS FPAR's potential suitability to improve erosion modelling via an integrated approach combining global and regional vegetation remote sensing products in the same study area as Schoettker, Phinn et al. (2010) and Schoettker, Scarth et al. (2010), a tropical semiarid catchment in Queensland.

\subsection{Overview and references}

In erosion modelling a so called $\mathrm{C}$-factor measures the combined effect of all the interrelated vegetative cover and crop management variables (Rosewell 1997). This definition has been used in empirical soil erosion models such as the Universal Soil Loss Equation (USLE) (Wischmeier and Smith 1978) and its subsequent Revised Universal Soil Loss Equation (RUSLE) (Renard, Smith et al. 1997). The C-factor is also commonly applied in varying forms in most other erosion models worldwide. Above ground vegetative C-factor (vCf) estimates for non-cropping areas under Australian conditions were published by Rosewell (1997).

Many water driven erosion models worldwide have been applied in recent decades and some have integrated remote sensing information (Vrieling 2006; USDA 2008; Searle and Ellis 2009). In Australia, however, to date most of the water driven erosion models applied still use the basic concept of the empirical USLE model, e.g. the SedNet whole-of catchment modelling (Lewis, Sherman et al. 2009). Aside from a number of major considerations which limit the utility of models, such as the USLE for, recent model applications by Searle and Ellis (2009) have improved the USLE utility in the semi-arid tropics of Queensland.
Despite these substantial research efforts, it is surprising that no study - to the knowledge of the author until this date - has integrated high temporal resolution remote sensing imagery to derive $\mathrm{vCf}$ estimates for use in erosion modelling other than by using classical vegetation indices (de Jong 1994; Lu, Prosser et al. 2003; Symeonakis and Drake 2004). However, in open plant communities, such the tropical semi-arid savannas of the study area, classical vegetation indices have been shown to perform less reliably for quantifying temporally variable TVC and its components and hence erosion or biomass modelling (van Leeuwen and Huete 1996). The derivation for or inclusion of remotely sensed structural characteristics of the TVC in erosion modelling is to date also very limited (Lu, Prosser et al. 2003; de Jong and Jetten 2007).

\section{METHODS}

\subsection{Deriving high temporal frequency vegetative cover} factor estimates

To account for the role vegetation plays in impeding soil loss, erosion models classically include so called cover subfactors that separate the total vegetation cover into two major vertical components: Canopy cover and surface cover (as for example described in USDA (2008) and Rosewell (1997). As most Australian plant communities feature a distinctive upper and a ground or lower stratum (Specht 1981), the separation of the TVC into a canopy and a surface cover is considered to adequately represent open plant communities that cover most of the Australian continent and the study area.

The equations typically used to derive $\mathrm{vCf}$ and subfactor estimates based on the earlier work by Wischmeier and Smith (1978) take the following form as published in Rosewell (1997):

\section{$\mathrm{C}=\mathrm{CanCov} *$ SurfCov}

, where CanCov is the canopy cover subfactor and SurfCov is the surface cover subfactor. The concept of vegetative cover subfactors applied here was taken from the Revised Universal Soil Loss Equation USDA (2008) and Rosewell (1997) for Australian conditions. The relevant equations to determine the vegetative cover's subfactors are commonly given as follows:

$$
\begin{aligned}
& \text { SurfCov }=e^{\left(a+b^{*} G C+c^{*} G C^{2}+d^{*} G C^{3}\right)} \\
& \text { CanCov }=1-(C C / 100) * e^{\left(-0.328^{*} h_{f}\right)} \\
& \text { with, } h_{f}=h_{b}+a_{s} * a_{g}\left(h_{t}-h_{b}\right) \\
& \text { or } \quad h_{f}=\frac{1}{3} * C H
\end{aligned}
$$

, where $a, b, c, d$ are coefficients given in Rosewell (1997), $C C$ is Canopy Cover (\%), $h_{f}$ is effective drop height, $h_{b}$ is height to the bottom of the canopy, $h_{t}$ is height to the top of the canopy, $a_{s}$ is a coefficient for canopy shape, $a_{g}$ for concentration of surface area within canopy given in (USDA 2008), and is $\mathrm{CH}$ is canopy height. The cover factor has commonly been determined simply as in eq. (2) for low wFPC areas (Searle and Ellis 2009) or as the product of eq. (2) and (3a or b) (USDA (2008) and Rosewell (1997), respectively).

The calculation of the dynamic vCf in this study were designed to advance and yet replicate useful aspects of more recent applications by USDA (2008) (RUSLE2 model) or conventional approaches by Rosewell (1997), to date used in 
Australia (SOILLOSS model), and variations of Rosewell's method as applied e.g. by Searle and Ellis (2009). This study calculated three vCf for the VSC representing the study area based on eq. 2 and eq. 1 using eq. $3 \mathrm{a}$ or $3 \mathrm{~b}$. A regionally developed Landsat TM and ETM+ overstorey's woody extent product (woody Foliage projective cover (wFPC)) from Queensland Department of Environment and Resource Management (QDERM) had been used to stratify the study area into VSC (Schoettker, Phinn et al. 2010).

The relevant variables for the subfactors were determined as follows: MODIS FPAR was used to approximate the GC variable in eq. 2 to establish its potential suitability for erosion modelling. To calculate the SurfCov we differentiated between more grassy and herbaceous VSC applying different coefficients $a, b, c$, and $d$ for eq. (2) (Rosewell 1997). For eq. 3, averages of $C C$ per VSC were derived from a relationship of wFPC to $C C$ by Scarth, Armston et al. (2008). Median $C H$ (incl. $h_{b}$ and $h_{t}$ ) was derived from ICESat for each VSC. The ICESat data had been processed byScarth, Armston et al. (2010). For eq. (3a), $h_{b}$ and $h_{t}$ were calculated from median ICESat pulses representing the upper and lower bounds of the canopy. The coefficients $a_{s}$ and $a_{g}$ in eq. (3a) were taken from (USDA 2008). For eq. (3b) $\mathrm{CH}$ was calculated as one third of the ICESat median centroid canopy height of each VSC as describe in Schoettker, Scarth et al. (2010). High temporal trajectories of $\mathrm{vCf}$ predictions for each of the three schemes to calculate the vCf (using eq. 2, and eq. 1 with $3 \mathrm{a}$ or $3 \mathrm{~b}$ ) were calculated and then extracted for representative and homogeneous regions of interest per VSC for the time span from 2000 to 2006 . The ROIs were widely distributed over the study area (sizes of ROIs varied between 3 and $10 \mathrm{~km}^{2}$.

\subsection{Modelling soil loss}

The (R)USLE is commonly known in the following form and soil loss is predicted as the product of six factors (Renard, Smith et al. 1997; Rosewell 1997):

$$
\text { A } \quad=\mathrm{R} * \mathrm{~K} * \mathrm{~L} * \mathrm{~S} * \mathrm{C} * \mathrm{P}
$$

, where $\mathrm{A}$ is average soil loss (t/ha/yr), $\mathrm{R}$ is rainfall erosivity (MJ mm ha/hr/yr), $\mathrm{K}$ is soil erodibility, $\mathrm{L}$ is slope length factor, $\mathrm{S}$ is slope steepness factor, $\mathrm{C}$ is crop and cover management factor (here vegetative cover factor (vCf)), and $\mathrm{P}$ is (due to lack of data usually assumed to be 1 (Searle and Ellis 2009)).

A temporarily and spatially explicit implementation of a modified version of the USLE was undertaken using a purpose written piece of C+ code as described in Searle et al. (2009).

The variable vegetative cover model of the USLE was based on the spatial and temporal processing of raster surfaces representing the components of the Revised USLE (RUSLE) (Renard, Smith et al. 1997). Daily soil loss predictions were made for pixels of $25 \mathrm{~m}$, that is, the MODIS FPAR time series had been resampled to $25 \mathrm{~m}$ (nearest neighbour resampling technique).

Due to the lack of field observations of high temporal frequency soil loss, only a relative validation of predicted soil losses from the study area could be achieved by exploring the relationship of the soil loss predictions to daily rainfall observations and to measurements of daily total suspended sediment TSS and daily streamflow at the outlet of the catchment and study area.

To evaluate the effect of the integration of the high-temporal frequency vCf predictions into the USLE soil loss predictions, comparisons to formerly made soil loss predictions were made. The relationship between average daily rainfall and (a) the to date commonly used, annual vCf (BGI_vCf based on Landsat imagery from QDERM) predictions and (b) this study's high temporal frequency vCf predictions using MODIS FPAR (eq. 2)
(MODIS FPAR_vCf) was determined over the whole time span of seven years for the areas of wFPC below 30\%. Those areas were chosen, since Searle and Ellis (2009) had applied their modified model previously to those areas only.

\subsection{Data used}

\subsubsection{Remotely sensed data}

A time series of the global MODIS FPAR (collection 4) data from 2000 to 2006 had been quality controlled and analysed for its sensitivity to regionally validate Landsat and MODIS based products in an earlier study (Schoettker, Phinn et al. 2010). The Landsat wFPC product used here to derive the VSC was based on a standardised Landsat TM and ETM+ time series developed at the QDERM (Danaher, Scarth et al. 2010). ICESat canopy height information was derived through waveform aggregation methodology and provided to the author by Scarth, Armston et al. (2010).

2.3.2 In situ measurements and rainfall data

In situ measurements of total suspended solid (TSS) (mg/l) for the wet seasons 2003/2004, 2004/2005, and 2005/2006 at the Myuna station, the station furthest downstream in the catchment of the study area, were provided by David Post, CSIRO. The data were recorded in hourly to minute-intervals and were here aggregated to average daily and cumulative TSS measures for comparison to daily predicted soil loss from the USLE model. Water quality and streamflow data were collected from David Post, CSIRO Land and Water Canberra and the only data recorded between 2000 and 2006. Daily rainfall surfaces and streamflow data (cumecs) were also provided by QDERM (http://watermonitoring.derm.qld.gov.au/host.htm).

\section{RESULTS AND DISCUSSION}

\subsection{High temporal frequency, remotely sensed vegetative cover factor estimates}

The time series of high temporal resolution vCf, resulting from eq. 2, 3a, and $3 \mathrm{~b}$ by assuming the SurfCov can be approximated as a function of the time series of MODIS FPAR, for four VSC in the study area are shown in Figure 1 (Scheme I, IIa, and IIb respectively). MODIS FPAR was used in that way because of its statistically significant sensitivity to green and non-green ground cover fractions, and despite the original eq. (2) being developed for ground cover products only. The vCf trajectories for the first four VSC are shown exemplarily; average wFPC for those four VSC are $0-2 \%, 3-10 \%, 11-30 \%$, and $31-50 \%$, respectively. Note, the higher the $\mathrm{vCf}$ value, the lower is the estimated protective function of the TVC. Overall higher vCf estimates and larger annual amplitudes can be found with decreasing wFPC percentages (lower VSC classes), suggesting a vegetative cover in those VSC classes with high biophysical variability.

A clear seasonality and distinct annual differences, such as the dry period peaking at the end of the year 2002, are visible for all three vCf schemes in all VSC (Figure 1). Average maximum $\mathrm{vCf}$ values in Figure 1 lie at 0.12 , minimum values at 0.05 . Differences between the vCf trajectories are generally very low but appear most prominent at the end of the dry seasons and more so in the higher wFPC classes (local maxima (for just one pixel) in differences of average $\mathrm{vCf}$ predictions in the study area lie at 0.04 and 0.048 for the dry season 2000 and 2004 respectively). It was expected, that the CanCov subfactor from eq. ( $3 a$ and b) affects the final vCf estimates more in VSC with denser wFPC or CC. Cover factor estimates of scheme (3b) are generally the lowest, which can be attributed to the fact that $h f$ 
were lowest for that eq. 3b. The underlying CanCov equations have been shown to be relatively insensitive to $\mathrm{CH}$ of more than $7 \mathrm{~m}$ (results not shown). Since the vCf estimates from eq. 2, 3a and $\mathrm{b}$ did not vary substantially the vCf estimates from eq. 2 are used in the following.
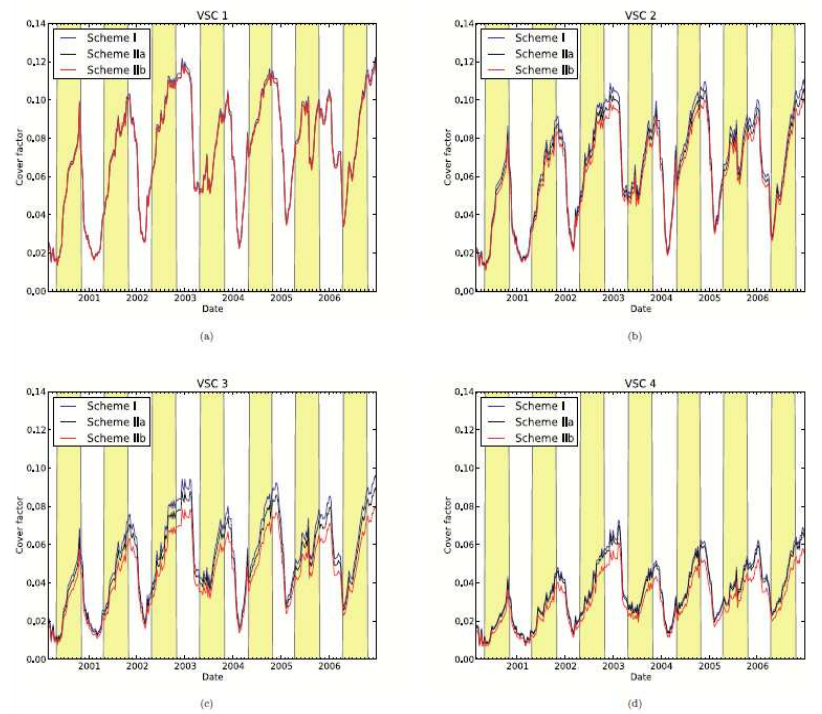

Figure 1. Time series of vCf predictions for four vegetation structural categories (VSC) (a to d) in the study area using MODIS FPAR to approximate the SurfCov subfactor (eq. 2; blue line), as the product of eq. 2 and the CanCov subfactor calculation from eq. $3 \mathrm{a}$ (green line) and eq. $3 \mathrm{~b}$ (red line). Those three vCf predictions are named Scheme I, IIa, and IIb above. Dry seasons are symbolised by light yellow bars. The mean number of MODIS FPAR observations per observation date were $2548,713,4191,1326,380$, and 129 for the ROIs of the VSC 1 to 6 respectively for the time period of $02 / 2000$ to $12 / 2006$.

\subsection{High temporal frequency soil loss predictions}

Figure 2 shows a time series of high temporal remotely sensed vCf (MODIS FPAR_vCf) (eq. 2), annual vCf (BGI_vCf), predicted soil erosion (t) (MODIS FPAR_E and BGI_E) and daily rainfall $(\mathrm{mm})$ for a randomly selected coordinate in the study.

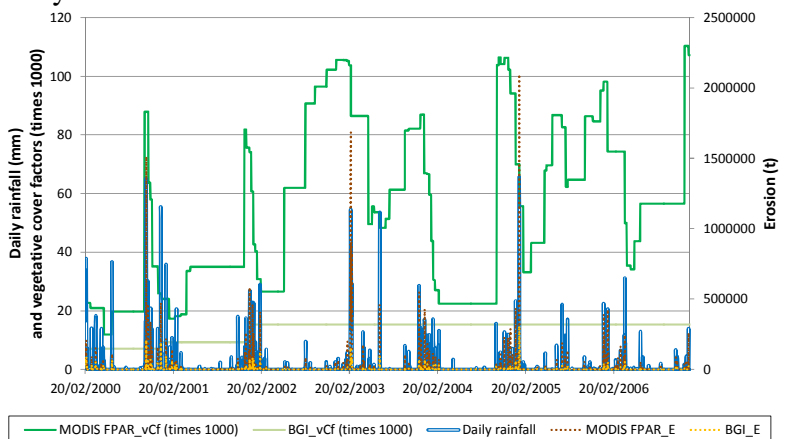

Figure 2. Time series of high temporal remotely sensed vCf (MODIS FPAR_vCf) (eq. 2; green line), annual vCf (BGI_vCf; bright green line), predicted soil erosion (t) (MODIS FPAR_E and BGI_E; dotted brown and orange lines respectively) and daily rainfall (mm; blue line) for a randomly selected coordinate in the study. Daily rainfall data from SILO (Jeffrey, Carter et al. 2001)
Soil loss predictions from the MODIS FPAR_vCf (eq. 2) coincide well with those from the annual BGI_vCf, while the soil loss predictions from eq. 2 are much higher. This is regarded as an indication of the dominance of the rainfall erosivity factor in the USLE. Generally, soil losses are mostly predicted to occur at the end of the dry seasons with high $\mathrm{vCf}$ values. The wet season 2004/2005 has the highest predicted soil losses from eq. 2 .

Whether the patterns of predicted soil loss for the study area have some agreement with events of streamflow and changed water quality at the outlet of the catchment (such as increased suspended solids) can be judged in comparison to an independent data set: in-stream measurements of cumulative daily total suspended solids (Figure 3).

Plots of time series of average daily streamflow at Myuna station, predicted soil loss (FparErosion) (t), and TSS measures (mg/l) show some similarities between the onset of events and the shape of event trajectories but other inconsistencies are quite prominent (Figure 3).
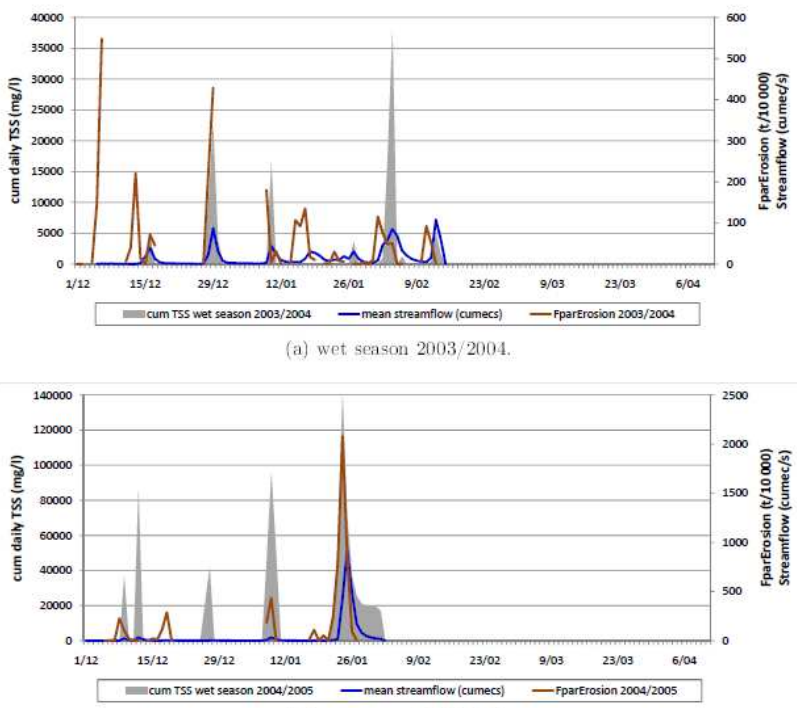

(b) wet season $2004 / 2005$

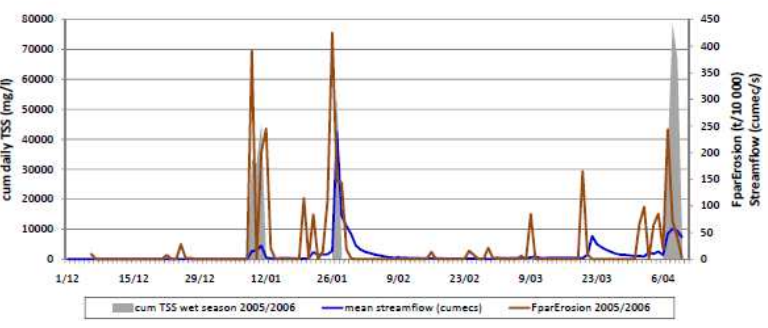

(c) wet season $2005 / 2006$.

Figure 3. Cumulative TSS (mg/l) (grey shade) and streamflow (cumecs/s) (blue line) at the Myuna station and predicted soil loss for the study area (FparErosion; in $t^{*} 10000$ for scaling purposes) (brown line) for three wet seasons (a) 2003/2004, (b)

2004/2005, and (c) 2005/2006. Predicted soil loss was calculated from the USLE using Scheme I in Figure 1or eq. 2 with MODIS FPAR as approximation for the GC. Data sources: TSS data by David Post, CSIRO; streamflow from QDERM. Note different scale for $\mathrm{y}$-axes in $\mathrm{a}, \mathrm{b}$, and $\mathrm{c}$.

Discharge events and wet seasons show characteristically different trajectories of all three variables. The wet season $2004 / 2005$ seems to have the closest fit between all three trajectories in comparison to the other wet seasons. 
Similarities between time series of TSS measures and soil loss predictions for certain parts of events are strong. A linear regression TSS (mg/l) and FparEros (t) suggests that $74 \%$ to $96 \%$ of the variability in TSS measures of certain sub-event over the wet season 2004/2005 could be explained by the MODIS FPAR based soil loss predictions, e.g. for the period between 9.12.2004 and 01.02.2005 (results not shown).

Integrating high temporal frequency vCf predictions into USLE is suggested to reduce the dominant effect the only other hightemporal frequency factor (R-factor) had on the soil loss predictions. A polynomial equation fitted to the relationship between daily soil loss predictions made using the high temporal frequency vCf estimates from eq. 2 using the MODIS FPAR time series and average daily rainfall has an $\mathrm{R}^{2}$ of 0.74 (Figure 5).

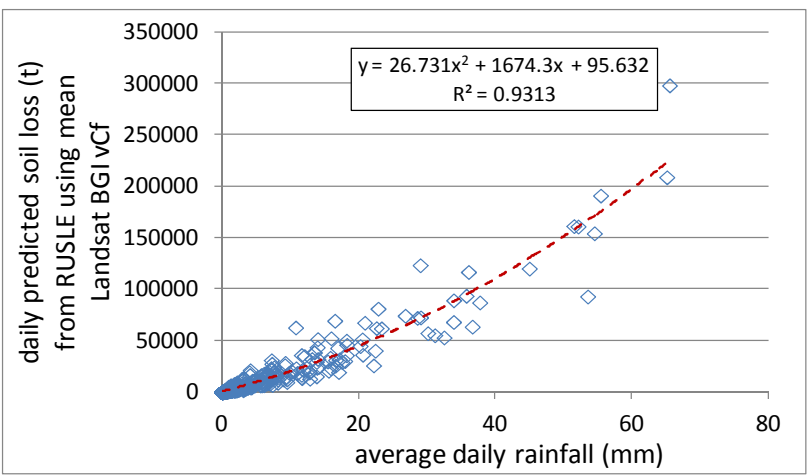

Figure 4. The relationship between daily soil loss predictions made using the classical, annual vCf estimates and average daily rainfall.

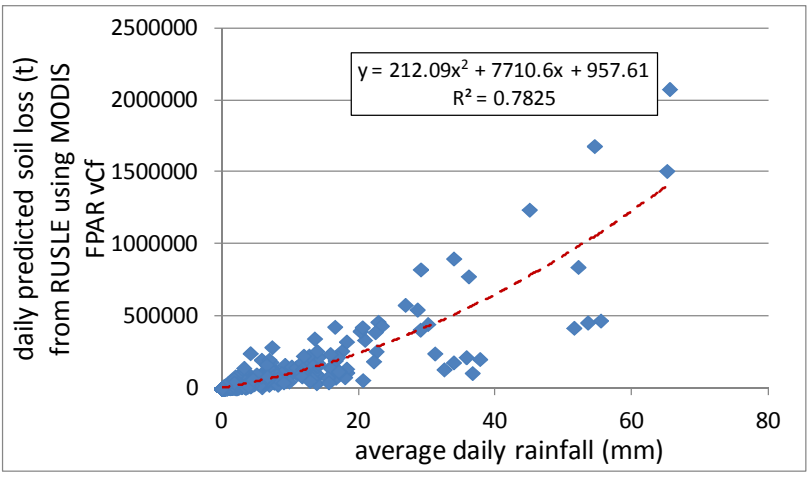

Figure 5. The relationship between daily soil loss predictions made using the high temporal frequency vCf estimates from eq.

2 using the MODIS FPAR time series and average daily rainfall.

In comparison, the relationship between soil loss predictions using the formerly used, annual vCf estimates and daily rainfall lies at $R^{2}$ of 0.93 (Figure ) $(\rho<0.001)$ (Figure 4 and 5). This is taken as an indication of the reduction of a strong temporal dependency of the USLE-based soil loss predictions on the daily rainfall/-erosivity factor when integrating high temporal frequency vCf estimates.

Limitations of this feasibility study are predominantly related to the use of the empirical USLE (e.g. development and validation and thus validity of the (R)USLE, no account for sediment transport or storage, sensitivity to variations and scale of input factors, no account for streambank or gully erosion, tendency to overestimate soil losses) (Kinnell 2005). It also has to be acknowledged that the interpretation of TSS concentrations is not the only factor to consider when interpreting the soil loss predictions. Also, the vCf equations were not developed for
FPAR measures. Nevertheless, Searle and Ellis (2009) suggest that their R/USLE variable cover model as applied in this study made sensible erosion estimates in semi-arid savannas in Australia and the MODIS FPAR has been shown to be sensitive to relevant vegetation properties (Schoettker, Scarth et al. 2010).

Whether the observed relationship between remotely sensed vCf based soil loss predictions and in stream TSS measures represents event-typical behaviour, such as supply limited or transport limited events, cannot be clearly identified at this stage without further field based data.

\section{CONCLUSION}

This study has provided the first suitability study of MODIS FPAR as an additional input parameter for estimating vCf in combination with information from ICESat and Landsat based VSC to improve existing erosion modelling studies and applications in a tropical semi-arid savanna ecosystem. Integrating those dynamic vCf into a modified version of the USLE, we presented the first high temporal frequency time series of soil loss predictions for the study area.

The high-temporal frequency $\mathrm{vCf}$ predictions of this thesis might be regarded as a new and promising approximation of the antecedent catchment conditions. We propose we have provided valuable results to show steps towards required improvement of existing erosion modelling approach in the study area, and possibly elsewhere. Yet, the soil loss predictions of this study have to be interpreted with care until a future study can validate the predictions.

Future research aims to identify drivers of observed temporal and spatial variations in soil loss predictions (e.g. by using physical based erosion models, multivariate analysis, including more recent discharge events and using the new collection of MODIS FPAR data). Further research also intends to validate the dynamic, remotely sensed $\mathrm{vCf}$ predictions with existing field data of ground cover and foliage projective cover, compare to $\mathrm{vCf}$ predictions based on a Landsat fractional ground cover product, a predicted Landsat FPAR product (Schoettker, Scarth et al. 2010). Developing FPAR based vCf equations and improved CanCov calculations is suggested as a target for future remote sensing studies that could combine optical, radar, and laser remote sensing techniques (Lucas, Lee et al. 2010).

To finally quantify the linkages between the spatially and temporally variable vegetative cover, rainfall, and erosion processes and their impact on the adjacent riverine and coastal environments is a continuing task for inter-disciplinary research.

\section{ACKNOWLEDGEMENTS}

This study was partly funded through a University of Queensland Research Scholarship and was supported by CSIRO Land and Water, Canberra (A/Prof Arnold Dekker). The authors would like to thank Colin Rosewell for his advice, Peter Scarth, and Robert Denham for their involvement in determining the potential usability of the MODIS FPAR in the study area.

A similar Figure to Figures 1 has been published in Schoettker, Scarth et al. (2010).

\section{REFERENCES}

Asner, G. P., 1998. Biophysical and biochemical sources of variability in canopy reflectance. Remote Sensing of Environment 64(3) pp. 234-253. 
Asner, G. P. and C. A. Wessman, 1997. Scaling PAR absorption from the leaf to landscape level in spatially heterogeneous ecosystems. Ecological Modelling 103(1) pp. 81-97.

Danaher, T., P. Scarth, et al., 2010. Ecosystem Function in Savannas: Measurement and Modelling at Landscape to Global Scales. M. J. Hill and N. P. Hanan, Taylor and Francis. Section 3. Remote Sensing of Biophysical and Biochemical Characteristics in Savannas How different remote sensing technologies contribute to measurement and understanding of savannas.

de Asis, A. M. and K. Omasa, 2007. Estimation of vegetation parameter for modeling soil erosion using linear Spectral Mixture Analysis of Landsat ETM data. ISPRS Journal of Photogrammetry $1 \&$ Remote Sensing 62 pp. 309-324.

de Jong, S. M., 1994. Derivation of vegetative variables from a Landsat TM image for modelling soil erosion. Earth Surface Processes and Landforms 19(2) pp. 165-178.

de Jong, S. M. and V. G. Jetten, 2007. Estimating spatial patterns of rainfall interception from remotely sensed vegetation indices and spectral mixture analysis. International Journal of Geographical Information Science 21(5) pp. 529 - 545.

Hutchings, P. and O. Hoegh-Guldberg, 2008. The Great Barrier Reef. Biology, Environment and Management. Collingwood, VIC, Australia, CSIRO Publishing.

Jeffrey, S. J., J. O. Carter, et al., 2001. Using spatial interpolation to construct a comprehensive archive of Australian climate data. Environmental Modelling and Software 16 pp. 309-330.

Kinnell, P. I. A., 2005. Why the universal soil loss equation and the revised version of it do not predict event erosion well. Hydrological Processes 19(3) pp. 851-854.

Knyazikhin, Y., J. Glassy, et al., 1999. MODIS Leaf Area Index (LAI) and Fraction of Photosynthetically Active Radiation Absorbed by Vegetation (FPAR) Product (MOD15) Algorithm Theoretical Basis Document, \{NASA Goddard Space Flight Center\}.

Lewis, S. E., B. S. Sherman, et al., 2009. Modelling and monitoring the sediment trapping efficiency and sediment dynamics of the Burdekin Falls Dam, Queensland, Australia pp. 4022-4028.

Lu, H., I. P. Prosser, et al., 2003. Predicting sheetwash and rill erosion over the Australian continent. Australian Journal of Soil Research 41(6) pp. 1037-1062.

Lucas, R. M., A. C. Lee, et al., 2010. Ecosystem Function in Savannas: Measurement and Modeling at Landscape to Global Scales. J. Hill and N. Hanan, Taylor I\& Francis Group. Section 3. Remote Sensing of Biophysical and Biochemical Characteristics in Savannas How different remote sensing technologies contribute to measurement and understanding of savannas.

Renard, K. G., D. D. Smith, et al., 1997. Predicting Soil loss erosion by water: A Guide to Conservation Planning With the Revised Universal Soil Loss Equation (RUSLE). Washington, DC, USA, \{United States Department of Agriculture\}.

Rosewell, C. J., 1997. Potential sources of sediments and nutrients: sheet and rill erosion and phosphorus sources, \{Australian Government .

Scarth, P., J. Armston, et al., 2008. On the Relationship between Crown Cover, Foliage Cover and Leaf Area Index. Proceedings of the 14th Australasian Remote
Sensing and Photogrammetry Conference (ARSPC), Darwin, Australia.

Scarth, P., J. Armston, et al., 2010. If you climb up a tree, you must climb down the same tree. But how high was it? Proceedings of the 15th Australasian Remote Sensing and Photogrammetry Conference (ARSPC), Alice Springs, NT.

Scarth, P., A. Röder, et al., 2010. Tracking Grazing Pressure and Climate Interaction - The Role of Landsat Fractional Cover in Time Series Analysis. Proceedings of the 15th Australasian Remote Sensing and Photogrammetry Conference (ARSPC), Alice Springs, NT.

Schoettker, B., S. Phinn, et al., 2010. How does the global Moderate Resolution Imaging Spectroradiometer (MODIS) Fraction of Photosynthetically Active Radiation (FPAR) product relate to regionally developed land cover and vegetation products in a semi-arid Australian savanna? Journal of Applied Remote Sensing 4(1) pp. 043538. doi: 043510.041117/043531.3463721.

Schoettker, B., P. Scarth, et al., 2010. Estimation of vegetation parameters from MODIS FPAR time series, Landsat TM and ETM+ products, and ICESat for soil erosion modelling. Proceedings of the 2010 IEEE International Geoscience and Remote Sensing Symposium.

Searle, R. D. and R. J. Ellis, 2009. Incorporating variable cover in erosion algorithms for grazing lands within catchment scale water quality models. 18th World IMACS Congress and MODSIM09 International Congress on Modelling and Simulation, 13-17 July, Cairns, Australia, Modelling and Simulation Society of Australia and New Zealand and International Association for Mathematics and Computers in Simulation.

Specht, R. L., 1981. General Characteristics of MediterraneanType Ecosystems. Proceedings of the symposium on dynamics and management of Mediterranean-type ecosystems, June 22-26, San Diego, California.

Symeonakis, E. and N. Drake, 2004. Monitoring desertification and land degradation over sub-Saharan Africa. International Journal of Remote Sensing 25(3) pp. 573-592.

Thomas, V., D. A. Finch, et al., 2006. Spatial modelling of the fraction of photosynthetically active radiation absorbed by a boreal mixedwood forest using a lidarhyperspectral approach. Agricultural and Forest Meteorology 140(1-4) pp. 287-307.

USDA, 2008. Science Documentation - Revised Universal Soil Loss Equation Version 2 (RUSLE2). Washington, D.C., USDA-Agricultural Research Service.

van Leeuwen, W. J. D. and A. R. Huete, 1996. Effects of standing litter on the biophysical interpretation of plant canopies with spectral indices. Remote Sensing of Environment 55(2) pp. 123-138.

Vrieling, A., 2006. Satellite remote sensing for water erosion assessment: A review. CATENA 65(1) pp. 2-18.

Wischmeier, W. H. and D. D. Smith, 1978. Predicting rainfall erosion losses: a guide to conservation planning, \{U.S. Dept. of Agriculture, Science and Education Administration . 